\title{
EXPERIMENTAL APPROVAL OF THE EFFICACY OF THE COMBINED COMPOSITION RECTAL CREAM NEW TEST-SAMPLES IN THE CONDITIONS OF ACUTE COMPLICATED ANAL FISSURE IN RATS
}

\author{
Ganna Zaychenko \\ Department of Pharmacology \\ Bogomolets National Medical University \\ 34 Peremogy ave., Kyiv, Ukraine, 03057 \\ anna.zajjchenko@gmail.com \\ Marina Stakhorska \\ Department of Clinical Pharmacology \\ Institute of Advanced Training of Pharmacy Specialists \\ National University of Pharmacy \\ 53 Pushkinska str., Kharkiv, Ukraine, 61002 \\ clinpharmacol_ipksph@nuph.edu.ua
}

\begin{abstract}
Anal fissure (AF) is one of the most common anorectal problems. The severity of the disease, the chronicity of the pathological process and frequent complications lead to a sharp deterioration in the quality of life of patients. An important place in the treatment of anal fissure is occupied by drugs that affect its key mechanism of pathogenesis, namely, reduce the muscle tone of the internal anal sphincter and have anti-inflammatory, analgesic, and reparative properties.

Aim: conducting of screening studies of the effectiveness of new test samples of rectal cream of the combined composition (RCCC) on the model of acute complicated anal fissure in rats and determining the optimal composition of the potential drug.

Materials and methods. The research was conducted on the basis of the Central Scientific Research Laboratory of the National Pharmaceutical University (CSRL NUPH) in the spring (April) season of 2015 on the female rats.

A study of test specimens of the rectal cream of the combined composition was performed on a modified model of acute anal fissure. The effectiveness of the treatment was evaluated in terms of (0 to 2$)$ severity of edema, hyperaemia, local bleeding, purulent necrotic processes, scapular formation, anatomical defect, and a general indicator of the severity of the pathological process (by the sum of the points for all the criteria that were analyzed). The level of proinflammatory PGE2 in serum was determined by the immune enzyme method.

Results. The RCCC sample No. 4 showed the most expressive therapeutic effect among the four samples under study, and had credible benefits to the inhibitory effect on purulent-necrotic processes, as expressed by the differences in the overall rate of the pathological process ( 6 days: $5.83 \pm 0.47$ points against $7.00 \pm 0.37 ; 7.83 \pm 0.31$ under the influence of RCCC No. 2 , No. 3, respectively, and for 11 days $5.00 \pm 1.03$ versus $6.83 \pm 1.28$ points $(\mathrm{p}=0.08$ ) under the influence of RCCC No. 1). The ability of RCCCs No. 1 and No. 4 to reduce the level of pro-inflammatory PGE2 in blood serum of rats compared with CP in 1.8 and 2.0 times, respectively, contributed to accelerating epithelization and scar formation. The advantages of RCCC No. 4 on the comparison of the ointment "Proctozan" with the reduction of the period of epithelization of the defect of the mucous membrane of the anal canal for 3 days (for 7 days - RCCC No. 4, for 10 days - ointment "Proctozan").
\end{abstract}

Conclusions. The rectal cream of the combined composition No. 4 showed the greatest efficacy, had advantages over the comparison ointment "Proctozan", and is promising for the creation on its basis a new drug for the treatment of anal fissures.

Keywords: rectal cream of combined composition, acute experimental anal fissure, prostaglandin E2.

DOI: $10.21303 / 2504-5679.2019 .00955$

\section{Introduction}

Anal fissure (AF) is one of the most common anorectal problems [1, 2]. According to various authors, the proportion of patients with AF in the structure of colorectal disease is from 8.5 to $16.0 \%$, women suffer from 1.5 to 2.0 times more often than men [3]. The disease dramatically worsens the quality of life of patients, makes them conflict and annoying, negatively affects the general and psychological state $[4,5]$. 
The pathological process with acute and chronic AF is characterized by a set of typical symptoms (inflammation, pain, microcirculatory vascular disorders and dysfunction of the sphincter apparatus) that develop simultaneously. One of the most important pathogenetic mechanisms that lead to tissue ischemia in the AF localization zone is the persistent spasm of the internal anal sphincter $[1,4]$.

The basis of the modern concept of pharmacotherapy AF $[4,6]$ is the use of drugs, such as calcium antagonists, nitrates, botulotoxin, whose action is aimed at eliminating the hypertonicity of the internal anal sphincter (IAS), which is the main factor in the chronicization of the pathological process $[5,7]$.

Most of the drugs presented today in the pharmaceutical market of Ukraine $[8,9]$ for the treatment of this pathology contain the following composition of active substances: local anaesthetics, glucocorticoids, non-steroidal anti-inflammatory drugs (NSAIDs), heparin, phenylephrine, ihtiol, vegetable components, mainly in the combined form, less commonly monopreparations. However, their application provides only symptomatic effects aimed at eliminating the inflammatory and pain syndrome, the sense of itching and burning in the anorectal area, stopping the bleeding and stimulating reparative processes. In fact, none of these drugs has a pathogenic effect, which helps to eliminate, first of all, spasm of muscle tissue IAS.

Thus, the analysis of the modern range of medicines in the Ukrainian pharmaceutical market shows a complete lack of drugs, the composition and effect of which would correspond to new approaches to medical treatment of AF $[4,6]$. Taking into account the above, the development and introduction into clinical practice of drugs of Ukrainian origin, which would be able to influence the main pathogenesis pathways and main clinical manifestations of AF, is one of the most urgent tasks of pharmacology and coloproctology.

\section{Aim at research}

Conducting screening studies on the efficacy of new test samples of rectal cream of compound composition (RCCC) on acute complicated AF models in rats and determining the optimal composition of a potential drug.

\section{Materials and Methods}

In the screening studies conducted in the spring (April) season in 2015, four RCCC test samples were used that were developed at "Institute for Single Crystals" of the National Academy of Sciences of Ukraine under the direction of doctor of pharmaceutical sciences, professor Lyapunov M. O.

RCCC test samples are white, homogeneous, odourless, opaque, containing active ingredients: diltiazem hydrochloride, lidocaine hydrochloride and methyluracil, but differ in their quantitative content. Data are given in Table 1.

Table 1

Composition of new test specimens of rectal cream of combined composition (RCCC) proposed for the treatment of anal fissure

\begin{tabular}{ccccc}
\hline Active ingredients & Test sample No. 1 & Test sample No. 2 & Test sample No. 3 & Test sample No.4 \\
\hline Diltiazem hydrochloride, $\mathrm{mg} / \mathrm{ml}$ & 40 & 40 & 40 & 20 \\
Lidocaine hydrochloride, $\mathrm{mg} / \mathrm{ml}$ & 30 & 30 & 30 & 30 \\
Methyluracil, $\mathrm{mg} / \mathrm{ml}$ & 50 & 0 & 100 & 50
\end{tabular}

The comparator preparation was rectal ointment "Proctozan" produced by Stada Arzneimittel AG, Germany (composition: $50 \mathrm{mg}$ bufexamac, $50 \mathrm{mg}$ bismuth subgallate, $50 \mathrm{mg}$ titanium dioxide, $5 \mathrm{mg}$ lidocaine hydrochloride) [8].

The study of the effectiveness of these RCCC test samples was performed on 36 non-linear white rats in females weighing 200-240 $\mathrm{g}$ in the model of acute complicated AF [10] under conditions 
of its modification [11]. Animals under novocaine anesthesia $(0.1 \mathrm{mg}$ of $0.5 \%$ solution of novocaine hydrochloride) were injected into the submucosal membrane of the posterior wall of the anal canal in the area of skin transition in anoderm $0.1 \mathrm{ml}$ of $2 \%$ formalin solution. AF was modelled by a scalpel dissection of the mucous membrane on the back of the anal canal (at 6 o'clock under the conditional dial at the position of the rat on the back), forming a defect - a linear wound of $5 \times 2 \times 1 \mathrm{~mm}$.

All animals were divided into 6 experimental groups of 6 rats each.

Group 1 - group of animals intact control; 2 - animals with non-treated AF (control pathology, CP); 3, 4, 5, 6 groups - animals with AF that were treated by RCCC No. 1, No. 2, No. 3, No. 4, respectively; group 7 - animals, who were treated with comparison ointment "Proctozan".

Treatment of rats began after 24 hours after AF recreation. The test samples and the comparator preparation were injected into the anal canal with an insulin syringe with a blunt needle in the amount of $0.3 \mathrm{ml}$ once daily throughout the experiment (12 days). At day 12, rats were withdrawn from the experiment by decapitation under a light ethereal anaesthetic.

The effect of the studied RCCC samples and "Proctozan" ointment on the course of the pathology was evaluated daily by the following parameters: severity of edema, hyperaemia, local bleeding, purulent necrotic processes, formation of scab and anatomical defect. Evaluation of pathological changes for each of the listed indicators was carried out on a scale: 0 points - absent or weak changes; 1 point - moderately pronounced changes; 2 points - pronounced changes. The effectiveness of treatment was characterized by each individual indicator under study and by the general indicator of the severity of the pathological process - the sum of the scores for all the indicators that were analyzed.

At the end of the experiment, in the blood serum of rats, the level of the major prostaglandin E2 $\left(\mathrm{PGE}_{2}\right)[12]$ was determined by the enzyme-linked immunosorbent assay method of the General Prostaglandin E2 ELISA Kit (EIAab, Cat. N: E 0538 Ge, China) according to the instructions. The incubation was carried out on a thermostat shaker ImmunoChem-2200 (HTI, USA), and the optical density of the samples was determined using a microplate reader of ImmunoChem-2100 (HTI, USA). For comparison with the magnitude of the physiological norm, $\mathrm{PGE}_{2}$ level was determined in intact animals (intact control, 6 rats).

The research was conducted in the Central Research Laboratory of the National Pharmaceutical University (CSRL NUPH), certified by the SEC of the Ministry of Health of Ukraine (certificate No. 058/15 dated December 8, 2015, valid until 07.12.2019). During the experiment, the animals were kept in the CSRL NUPH vivarium at a temperature of $20-22{ }^{\circ} \mathrm{C}$ and $50 \%$ humidity in a well ventilated room, under the conditions of natural day and night light (April 2015) with free access to food and water.

All manipulations with animals were carried out in accordance with the requirements of GLP, the recommendations of the SEC of the Ministry of Health of Ukraine, the National "General ethical principles of animal experiments (Ukraine, 2001), the Law of Ukraine No. 3447-IV of February 21, 2006, as amended "On the protection of animals from cruel treatment" by the decision of the first national congress on bioethics (Kyiv, 2007) [13] and "European Union Directive 2010/63 / EU on the protection of animals used for scientific purposes" [146].

The statistical processing of the obtained results was carried out using parametric (Student's criterion) and non-parametric (Kruskal-Wallis criterion) methods of statistics. The level of significance $\mathrm{p}<0.05[15]$ was adopted.

\section{Results of researches}

After simulating acute AF, the development of pathological process in animals from the $\mathrm{CP}$ group was characterized by a certain dynamics of clinical symptoms: edema, hyperaemia, local bleeding, and purulent necrotic processes.

Inflammation, evaluated for the severity of such clinical symptoms as swelling and hyperaemia, were maximum ( $2.00 \pm 0.00$ points) from 1 to 10 days with a slight decrease over the last two days of the trial. Local bleeding occurred only on the first day and was present in a small number of animals (in two of six) at the end of the experiment (11 days). Manifestations of purulent necrotic process in untreated animals began with 4 days $(0.67 \pm 0.21$ points $)$ and reached a maximum 
of 9 and 10 days ( $1.67 \pm 0.33$ points), indicating the probable accession of the infection and chronic pathological process (Fig. 1).

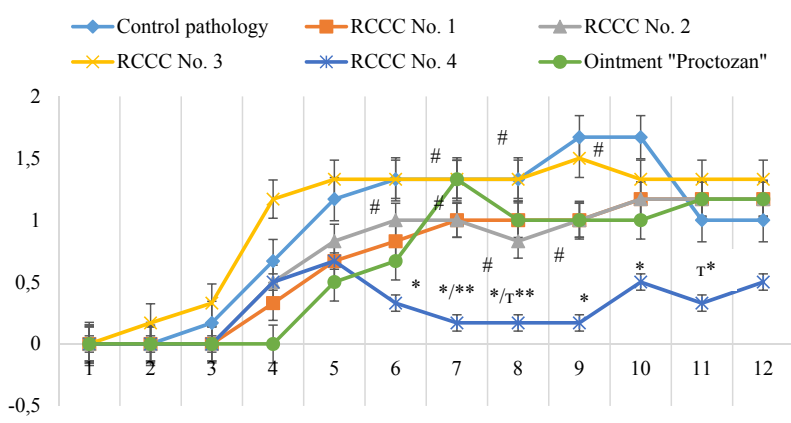

Fig. 1. Significance of purulent necrotic process under the influence of RCCC test specimens on the model of acute complicated anal fissure in rats (points): ${ }^{*}$ - significant differences in control pathology (nonparametric criterion of Kruskal-Wallis), $\mathrm{p}<0.05$; $* *$ - the differences are relative to the drug comparison ointment "Proctozan" (nonparametric criterion Kruskal-Wallis), $\mathrm{p}<0.05$; \# - the differences are relative to RCCC № 4 (nonparametric criterion of Kruskal-Wallis), $\mathrm{p}<0.05$;

$$
\mathrm{T} \text { - trend } 0.050<\mathrm{p}<0.1
$$

The expressiveness of the scab formation was variable: it marked its appearance from 4 to 6 days, the absence in the period of intensification of the development of purulent necrotic processes from 6 to 10 days and during the last two days, due to a decrease in necrosis of the mucous membrane of the anal canal in the affected area. The severity of the anatomical defect in animals from the CP group was maximal (2.00 \pm 0.00 points) from day 1 to day 9 of the experiment and slightly decreased (to $1.83 \pm 0.17$ points) during the last three days of the experiment.

The general indicator of the severity of the pathological process was $8.00 \pm 0.00$ points for the first day, decreased to a minimum value of $6.33 \pm 0.26$ points for 2 and 3 days, followed by a maximum increase to $7.67 \pm 0.33$ points at 9 day At day 12 of the experiment, the severity of the pathological process in untreated animals was quite significant at the level of $7.00 \pm 0.68$ points out of 12.00 possible (Fig. 2).

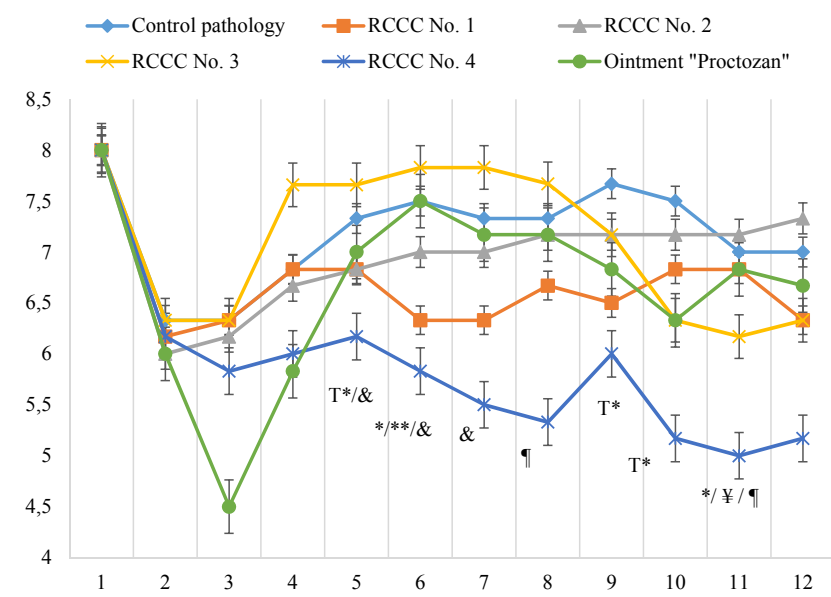

Fig. 2. The general indicator of the severity of the pathological process (in total, according to the studied parameters) under the influence of RCCC test samples on the model of acute complicated anal fissure in rats (points): * - significant differences in control pathology (nonparametric criterion of Kruskal-Wallis), $\mathrm{p}<0.05$; ** - the differences between the "Proctozan" ointment (nonparametric Kruskal-Wallis criterion) $\mathrm{p}<0.05$; $¥$ - the differences are relative to RCCC No. 1 (nonparametric criterion of Kruskal-Wallis), $\mathrm{p}<0.05 ; \boldsymbol{q}$ - the differences are relative to RCCC No. 2 (nonparametric criterion of Kruskal-Wallis), $\mathrm{p}<0.05$; \& - the differences are relative to RCCC

No. 3 (nonparametric criterion of Kruskal-Wallis), $\mathrm{p}<0.05$; $\mathrm{T}-$ trend, $0.050<\mathrm{p}<0.1$ 
Comparative drug, "Proctozan" ointment, on the background of complicated acute AF showed a significant anti-swelling $(1.17 \pm 0.17$ points versus $2.00 \pm 0.00$ points of $C P)$ and antihyperemic effects, the maximum of which occurred at 3 days. Since 4 days, the therapeutic effectiveness of "Proctozan" ointment has decreased and during the period from 5 to 12 days of the experiment there was no difference in the overall indicator of the severity of the pathological process in relation to the CP group (Fig. 2).

Two RCCC test samples, number 1 and number 4, starting from 5 days, demonstrated the ability to reduce the expressiveness of purulent necrotic processes and accelerated reparation. At day 7 of the experiment in single rats under the influence of RCCC No. 4, the beginning of epithelization was noted, and the first case of epithelization in animals treated with "Proctozan" ointment was recorded for only 10 days.

At 10-12 days, the severity of purulent-necrotic processes in some rats that received test specimens No. 1, No. 2, No. 3, and the comparison drug, increased somewhat.

RCCC No. 4 showed the most expressive therapeutic effect and had significant benefits to the inhibitory effect on purulent-necrotic processes (for 7 days, the test was 0.17 points versus $1.00 \pm 0.26,1.00 \pm 0.37$ and $1.33 \pm 0.33$ points, respectively, under the action RCCC No. 1, No. 2, No. 3 ); anatomical defect (for 4 days $1.50 \pm 0.22$ points against $2.00 \pm 0.00$ points under the influence of RCCC No. 1, No. 2, No. 3 ( $\mathrm{p}=0.05)$ ). The reliable differences of the general indicator of the expressiveness of the pathological process for 6 days are established: $5.83 \pm 0.47$ points versus $7.00 \pm 0.37$; $7.83 \pm 0.31$ under the influence of RCCC No. 2 and No. 3, respectively, and for 11 days $(5.00 \pm 1.03$ vs. $6.83 \pm 1.28$ points $(\mathrm{p}=0.08)$ under the influence of RCCC No. 1$)$.

Also, the effect of RCCC test samples on the level of PGE2 in blood serum of rats was evaluated. Data are given in Table 2.

\section{Table 2}

The content of PGE2 in blood serum of rats with acute anal fissures at 12 days of the experiment under the influence of RCCC test specimens ( $\mathrm{n}=6$ )

\begin{tabular}{cc}
\hline Experimental group & The content of PGE2 in blood serum, pcg/ml \\
\hline Intact control & $230.3 \pm 57.6$ \\
CP & $485.5 \pm 82.6^{*}$ \\
RCCC No. 1 & $275.8 \pm 13.4^{* *}$ \\
RCCC No. 2 & $354.8 \pm 23.3^{* * *}$ \\
RCCC No. 3 & $361.5 \pm 54.8^{* * *}$ \\
RCCC No. 4 & $245.0 \pm 60.1^{* *}$ \\
«Proctozan» ointment & $237.9 \pm 8.5^{* *}$
\end{tabular}

Note: * the differences are reliable for intact control, $p<0.05$; ** - the differences are reliable for the CP, $p<0.05$; *** - the differences are reliable with respect to the drug comparison ointment "Proctozan", $p<0.05$

The level of PGE2 in the blood serum of rats from the CP group at 12 days of the experiment was 2.1 times higher $(\mathrm{p}<0.05)$ higher than intact control. The content of PGE2 in blood serum of animals treated with RCCC No. 2 and No. 3 was also high (354.8 \pm 23.3 and $361.5 \pm 54.8)$, almost at the level of animals in the CP group. At the same time, there was a significant decrease in PGE2 to the level of intact control in rats treated with RCCC No. 1 and No. 4 (respectively, $75.8 \pm 13.4$ and 245.0 \pm 60.1 ). "Proctozan" ointment contributed to reduce the level of PGE2 to intact control.

\section{Discussion}

It was established that the reproductive model of the acute complicated anal fissure in rats was characterized by the progressive dynamics of edema, hyperaemia, significant pronounced purulent necrotic processes, the formation of scab, and the formation of anatomical defect, which 
remained until the end of the experiment. Such dynamics of pathological changes in the control group of animals is probably related to the action of formalin, which causes the destruction of proteins and other cellular components and leads to necrosis of tissues [11]. The level of $\mathrm{PGE}_{2}$ in blood serum from the CP group of rats, despite the individual cases of complete healing of the anatomical defect at day 12 of the experiment, remained significantly elevated by 2.1 times $(p<0.05)$ compared with intact control.

Two RCCC test samples, No. 1 and No. 4, starting from 5 days, demonstrated the ability to reduce the expressiveness of purulent necrotic processes and accelerated reparation. At day 7 of the experiment, under the influence of the RCCC sample number 4, epithelization was noted in one rat, and the first case of epithelization in animals treated with "Proctozan" ointment was recorded for only 10 days.

The expressiveness of purulent necrotic processes in some rats who received test specimens No. 1, No. 2, No. 3 and the comparison preparation, increased somewhat for 10-12 days, indicating the tendency to chronization of the process.

RCCC No. 4 showed the most expressive therapeutic effect and had credible advantages over RCCC No. 1, No. 2 and No. 3 for the inhibitory effect on purulent-necrotic processes on day 7 of the trial; on the severity of the anatomical defect (4 days), which was expressed by the differences in the overall indicator of the severity of the pathological process by 6 days, compared with RCCC No. 2, No. 3 and 11 days compared with RCCC No. 1.

The comparison drug "Proctozan", which was used in the experiment, made the most expressive anti-swelling and antihyperemic effects, with a maximum effect of 3 days. It had a significant anti-inflammatory effect and superiority to all the test samples tested, which in contrast to it practically did not affect the severity of inflammation. This fact, obviously, is related to the presence of "Proctozan" ointment, a buffer that acts according to the mechanism of action, is a typical NSAID [16] and distinguishes it from the test samples tested, which do not contain any components that exhibit would have a clear anti-inflammatory effect. Since 4 days, the therapeutic efficacy of the "Proctozan" ointment has decreased and during the period from 5 to 12 days of the experiment, there was no difference in the overall indicator of the severity of the pathological process in relation to the CP group. The explanation for such an action by the "Proctozan" ointment is more likely to be that all anti-inflammatory agents, reducing the severity of the changes that make up the nature of acute inflammation, eliminate its completion and inhibit the reparative processes $[17,18]$, as well as those available in its composition does not reduce the tone of the internal anal sphincter muscles.

Given the important role of prostaglandins, in particular $\mathrm{PGE}_{2}$, in initiating and developing inflammation (redness, swelling, pain) accompanying the wound [12], it was advisable to evaluate the effect of the tested RCCC samples on their blood serum level in rats.

The level of $\mathrm{PGE}_{2}$ in the blood serum of rats from the CP group, despite the individual cases of complete healing of the anatomical defect at day 12 of the experiment, remained significantly elevated, which is probably due to the spraying of pronounced acute inflammatory changes to reparative processes that have already been activated. Such a character of the development of pathology is accompanied by excessive accumulation of connective tissue elements, a violation of epithelization and the formation of scar $[19,20]$. Low levels of $\mathrm{PGE}_{2}$ in blood serum of animals treated with "Proctozan" ointment were due to the presence of an anti-inflammatory agent, bufexamac, which could lower the level of $\mathrm{PGE}_{2}$ [8]. However, it has been established that the "Proctozan" ointment was somewhat less effective compared to the RCCC sample No. 4 as a general indicator of the pathological process.

The content of $\mathrm{PGE}_{2}$ in blood serum of animals treated with RCCC No. 2 and No. 3 was practically at the level of animals from the $\mathrm{CP}$ group, indicating that the pathological process was chronic. At the same time, there was a significant decrease in $\mathrm{PGE}_{2}$ levels to the level of intact control in rats treated with RCCC No. 1 and No. 4, indicating attenuation of inflammation after 10 days of the experiment against the backdrop of positive dynamics of reparative processes.

Consequently, according to the results of screening studies, a perspective test for RCCC No. 4 was found to be the most effective in the acute complicated AF model. 


\section{Conclusions}

1. Model pathology of acute complicated AF in rats was characterized by the progressive dynamics of development of clinical symptoms (edema, hyperaemia), expressiveness of purulent necrotic processes, formation of scab, and formation of anatomical defect against a background of elevated level of pro-inflammatory $\mathrm{PGE}_{2}$ in 2.1 times $(\mathrm{p}<0.05)$ for 12 days, indicating the chronicization of the pathological process.

2. RCCC test sample No. 4 showed the most expressive therapeutic effect among the four test samples and had significant advantages over the inhibitory effect on purulent necrotic processes, as evidenced by the differences in the overall rate of the pathological process (6 days: $5.83 \pm 0.47$ points against $7.00 \pm 0.37,7.83 \pm 0.31$ under the influence of RCCC No. 2 and No. 3, respectively, and for 11 days $5.00 \pm 1.03$ against $6.83 \pm 1.28$ points $(\mathrm{p}=0.08)$ under the influence of RCCC No. 1). The ability of RCCCs No. 1 and No. 4 to reduce the level of pro-inflammatory $\mathrm{PGE}_{2}$ in blood serum of rats compared with $\mathrm{CP}$ in 1.8 and 2.0 times, respectively, contributed to accelerating epithelization and scar formation.

3. The advantages of RCCC No. 4 on the comparison ointment "Proctozan" with the reduction of the period of epithelization of the mucous membrane defect of the anal canal for 3 days were established (in 7 days RCCC No. 4, in 10 days "Proctozan" ointment was better).

4. The results of the RCCC No. 4 largest therapeutic effects substantiate the optimality of its composition and the expediency of further in-depth study to create a new domestic drug for the treatment of coloproctological diseases, in particular AF.

\section{References}

[1] Schlichtemeier, S., Engel, A. (2016). Anal fissure. Australian Prescriber, 39 (1), 14-17. doi: http://doi.org/10.18773/austprescr.2016.007

[2] Zaghiyan, K., Fleshner, P. (2011). Anal Fissure. Clinics in Colon and Rectal Surgery, 24 (1), 22-30. doi: http://doi.org/ $10.1055 / \mathrm{s}-0031-1272820$

[3] Giridhar, C. M. (2014). A Comparative Study of Lateral Sphincterotomy and $2 \%$ Diltiazem Gel Local Application in the Treatment of Chronic Fissure in A NO. Journal of Clinical and Diagnostic Research, 8 (10), NC01-NC02. doi: http://doi.org/10.7860/ jedr/2014/10480.4925

[4] Stewart, D. B., Gaertner, W., Glasgow, S., Migaly, J., Feingold, D., Steele, S. R. (2017). Clinical Practice Guideline for the Management of Anal Fissures. Diseases of the Colon \& Rectum, 60 (1), 7-14. doi: http://doi.org/10.1097/dcr.0000000000000735

[5] Othman, I. (2010). Bilateral versus posterior injection of botulinum toxin in the internal anal sphincter for the treatment of acute anal fissure. South African Journal of Surgery, 48 (1), 20-22.

[6] Ommer, A., Herold, A., Berg, E., Fürst, A., Post, S., Ruppert, R. et. al. (2017). German S3 guidelines: anal abscess and fistula (second revised version). Langenbeck's Archives of Surgery, 402 (2), 191-201. doi: http://doi.org/10.1007/s00423-017-1563-Z

[7] Nelson, R. L., Thomas, K., Morgan, J., Jones, A. (2012). Non surgical therapy for anal fissure. Cochrane Database of Systematic Reviews, 2. doi: http://doi.org/10.1002/14651858.cd003431.pub3

[8] Kovalenko, V. N. (Ed.) (2015). Kompendium 2015 lekarstvennye preparaty. Kyiv: Morion, 2320.

[9] Derzhanyi reiestr likarskykh zasobiv. Available at: http://www.drlz.com.ua/

[10] Gainutdinov, F. M., Iapparova, A. A., Gumerova, G. T. (2008). Morfologicheskaia sravnitelnaia otsenka effektivnosti primeneniia suppozitorii pri eksperimentalnoi modeli ostroi treshchiny analnogo kanala. Meditsinskii vestnik Bashkortostana, $3(5), 44-46$.

[11] Zaychenko, H. V., Stakhorska, M. O., Liapunov, M. O., Faizullin, O. V. (2018). Udoskonalennia eksperymentalnoho metodu vidtvorennia hostroi analnoi trishchyny. Kyiv, 1, Z problemy «Farmatsiia», 4.

[12] Prostahlandyny: shliakhy biosyntezu ta klitynni dzherela. Available at: https://studopedia.info/1-112471.html

[13] Stefanov, O. V. (Ed.) (2001). Doklinichni doslidzhennia likarskykh zasobiv. Kyiv: Avitsena, 74-97.

[14] Directive 2010/63/EU of the European Parliament and of the Council of 22 September 2010 on the protection of animals used for scientific purposes (2010). Official Journal of the European Union, L276, 33-79.

[15] Lapach, S. N., Chubenko, A. V., Babich, P. N. (2000). Statisticheskie metody v biologicheskikh issledovaniiakh s ispolzovaniem Excel. Kyiv: Morion, 320.

[16] Brogden, R. N., Pinder, R. M., Sawyer, P. R., Speight, T. M., Avery, G. S. (1975). Bufexamac: a review of its pharmacological properties and therapeutic efficacy in inflammatory dermatoses. Drugs, 10 (5-6), 351-356. doi: http://doi.org/10.2165/00003495197510050-00005 
[17] Chazaud, B. (2015). Inflammation during skeletal muscle regeneration and tissue remodeling: application to exercise-induced muscle damage management. Immunology and Cell Biology, 94 (2), 140-145. doi: http://doi.org/10.1038/icb.2015.97

[18] Duchesne, E., Dufresne, S. S., Dumont, N. A. (2017). Impact of Inflammation and Anti-inflammatory Modalities on Skeletal Muscle Healing: From Fundamental Research to the Clinic. Physical Therapy, 97 (8), 807-817. doi: http://doi.org/10.1093/ptj/pzx056

[19] Iizuka, M., Konno, S. (2011). Wound healing of intestinal epithelial cells. World Journal of Gastroenterology, 17 (17), $2161-$ 2171. doi: http://doi.org/10.3748/wjg.v17.i17.2161

[20] Nakanishi, M., Rosenberg, D. W. (2012). Multifaceted roles of PGE2 in inflammation and cancer. Seminars in Immunopathology, 35 (2), 123-137. doi: http://doi.org/10.1007/s00281-012-0342-8

\title{
THE METHOD OF FORECASTING OF THE INDICATORS FOR DRUG REIMBURSEMENT TO PATIENTS WITH CARDIOVASCULAR DISEASES IN UKRAINE
}

\author{
Alla Nemchenko \\ Department of Organization and Economy of Pharmacy \\ National University of Pharmacy \\ 53 Pushkinska str., Kharkiv, Ukraine, 61002 \\ Viktoriya Nazarkina \\ Department of Organization and Economy of Pharmacy \\ National University of Pharmacy \\ 53 Pushkinska str., Kharkiv, Ukraine, 61002 \\ Yuliia Kurylenko \\ Department of Organization and Economy of Pharmacy \\ National University of Pharmacy \\ 53 Pushkinska str., Kharkiv, Ukraine, 61002
}

\begin{abstract}
The aim of the study is to develop a method for forecasting the indicators for drug reimbursement to patients with cardiovascular diseases (CVD) in Ukraine within the framework of the government program "Available medicines".

Materials and methods: materials of the State Statistics Service of Ukraine and medical records of patients with CVD, who were prescribed with medicines according to the government program, were used in the study.

Results: according to the method proposed for forecasting the volume of drug reimbursement to patients with CVD under the government program it has been found that Enalapril has the highest indicator - 10916.4 USD thousand in 2019 and 10736.8 USD thousand in 2020. Clopidogrel takes the second position - 12108.13 USD thousand and 11908.24 USD thousand, while Amlodipine occupies the third position - 9105.60 USD thousand and 8955.28 USD thousand.

Among the medicines not included in the government program, but prescribed rather frequently the largest forecasting amount required for reimbursement (in case of inclusion in the program) is 18910.55 USD thousand in 2019 and 18598.36 USD thousand in 2020 for Magnicor, and the least amount is 444.55 USD thousand and 437.22 USD thousand for Acetylsalicylic acid, respectively.

Conclusions. The government program to provide patients with effective and affordable medicines has a significant impact on reforming the healthcare system of Ukraine. The study conducted can be used to expand the government program in the process of formation and distribution of budget funds.
\end{abstract}

Keywords: cardiovascular diseases, forecasting, reimbursement, medicines, healthcare. 